\title{
Academic Research in Marketing and Business School Health: Limiters and Improvement Opportunities
}

\author{
Stefan Stremersch ${ }^{*}$ \\ Russell S. Winer**
}

* Chair of Marketing and Desiderius Erasmus Distinguished Chair of Economics, Erasmus School of Economics, Erasmus University Rotterdam, the Netherlands, and Professor of Marketing, IESE Business School, Universidad de Navarra, Spain. Email: stremersch@ese.eur.nl

**William Joyce Professor of Marketing, Stern School of Business, New York University. Email: rwiner@stern.nyu.edu

We appreciate the comments provided on earlier drafts of this manuscript by Nuno Camacho, Vijay Hariharan, Eitan Muller, John Roberts, Roland Rust, Rick Staelin, Jan-Benedict Steenkamp, and Julian Villanueva. This version was submitted to Journal of Marketing in October 2018, with a revision invited in January 2019. The authors are currently working on a new version of this manuscript. 


\title{
Academic Research in Marketing and Business School Health: Limiters and Improvement Opportunities
}

\begin{abstract}
Academic research in marketing is of key importance to the health of business schools. However, there has been considerable debate in recent years whether academic research in marketing, and business in general, delivers enough on this promise. Our goal is to add a coherent and novel faculty management perspective to this debate. We identify three limiters in the faculty management system that restrict the impact academic research in marketing may have on business school health: (1) the imperfect metrics used to evaluate marketing academics that focus primarily on quantity, (2) the weak professional alignment between marketing academics and professionals relevant to marketing, and (3) the incentives for marketing academics that have started to emphasize extrinsic rewards such as bonuses for publications. In response to these limiters, we offer three improvements for increasing the impact marketing can have on business school health. These include: (1) supplementing the quantitative metrics with a qualitative assessment of the work, (2) socializing marketing academics into the practice of marketing, and (3) strengthening intrinsic rewards and reducing extrinsic rewards.
\end{abstract}

Keywords: marketing, research, faculty, business school, managerial relevance, citation, scientometrics, metrics, incentives, rewards, rigor. 


\section{INTRODUCTION}

In recent years, marketing scholars have raised serious concerns with the state of academic research in marketing. Lehmann et al. (2011) argued that marketing academia has sacrificed relevance, communicability and simplicity for sophistication. Reibstein et al. (2009) and Lilien (2011) noted a widening gap between the interests of academic marketers and the needs of marketing executives. Roberts et al. (2014) found that academic impact and impact on practice rarely co-occur among articles in premier journals. Marketing academia has also faced a number of noteworthy science integrity cases, questioning publication practices.

While each field has its own particular characteristics, some of these concerns have been echoed by management scholars. Pfeffer and Fong (2002) argued that business school research does not influence management practice much. Bennis and O'Toole (2005) and Schoemaker (2008) questioned the applicability of the science model as is common in chemistry or economics to business schools which are, in their minds, professional schools, similar to law schools. "When applied to business - essentially a human activity in which judgements are made with messy, incomplete and incoherent data - statistical and methodological wizardry can blind rather than illuminate.” (p. 3; Bennis and O'Toole 2005). This echo has resulted in the recent $\left(2017^{1}\right)$ formation of the Community for Responsible Research in Business and Management which aims to address the "Crisis of Rigor" and the "Crisis of Relevance" of business school research. Rigor and relevance are interrelated, as research that lacks rigor cannot be relevant (see also Vermeulen 2005).

\footnotetext{
${ }^{1}$ The www.rbbm.network website lists the first initiation of the project in 2014. Only in 2017, though, was a first position paper with a group of co-signers shared publicly, so we regard that as the real birth of the rbbm network.
} 
This state-of-affairs affects business schools. Business schools consider academic research as one of the main pillars in their business model and allocate a large part of their resources to it (e.g., faculty time, labs, research budgets). Therefore, the limiters to the impact of academic research on business school health, and ways to improve it, are of prime interest to business school management and business school stakeholders such as companies, funding bodies, government, and society at large.

Our goal is to add a faculty management perspective to the debate on the current state of academic research in business schools and, in particular, in marketing. Our contribution is, first, to organize faculty management factors that limit the impact of academic research in marketing on business school health including: (1) faculty research performance measurement ('metrics'); (2) faculty socialization ('professional alignment'); and (3) faculty rewards ('incentives'). Second, we derive a set of specific recommendations to improve the impact of academic research in marketing on business school health including (1) supplementing quantitative metrics used to characterize an academic's publication record with a number of qualitative measures; (2) improving the socialization of marketing academics with practice, and (3) strengthening the intrinsic rewards produced by research while limiting the role of extrinsic rewards. We start by reviewing why we - and others - believe academic research in marketing is fundamental to business school health.

\section{WHY ACADEMIC RESEARCH IN MARKETING IS FUNDAMENTAL TO BUSINESS SCHOOL HEALTH}

Our conceptualization is grounded on the fundamental conviction that rigorous academic research in marketing is fundamental to business school health. Drucker (1954) is often quoted on the importance of marketing in a business when he said that any business has only two basic functions: marketing and innovation. Strong marketing leaders offer positive financial returns to 
the organizations that employ them, both in the short and the long run and both for new ventures as well as Fortune 500 firms (Feng, et al. 2015; Germann, et al. 2015; Homburg et a. 2014; Moorman and Rust 1999). The importance of marketing to businesses makes marketing an area fundamental to business school health.

In the past, marketing academics have had a strong influence in training and shaping strong leaders in practice. Through their writings, academics such as Philip Kotler and David Aaker have defined marketing as a professional field to a much larger extent than any non-academic can claim. These scholars and many others have developed textbooks, trained generations of undergraduates and MBAs, taught executives, and consulted to create the well-trained cadre of senior marketing executives that exists today. Marketing academics have also trained general managers and managers in other fields on marketing. In some sense, we have become victims of our success in that one of the main reasons for the waning influence of the marketing department in the firm is the organization-wide adoption of the marketing concept. This can be considered a victory of marketing thought (Verhoef and Leeflang 2009) in which many marketing academics played a pioneering and pivotal role.

Marketing as a research discipline in business schools, neck-and-neck with finance and operations research, has also led the increase in research rigor, ahead of established fields such as accounting, strategy, organization, IS, and HR, as well as newer fields such as entrepreneurship, leadership and ethics. Marketing faculty such as Frank Bass, Edgar Pessemier, Ronald Frank, and Philip Kotler attended the original workshops by the Institute of Basic Mathematics for Application to Business, which was founded as a response to the report issued in 1959 by the Ford Foundation that was sharply critical of U.S. business school education (see Neslin and Winer 2014). The increase in marketing research rigor that followed, while first being confined to the 
U.S., has since the 1970s globally proliferated (Stremersch and Verhoef 2005), starting in Western Europe, today diffusing further to East and South Europe and Asia. Academic marketing research has clearly contributed over the past 50-60 years to our understanding of how the marketing mix, such as price and communication, affects sales, how different segments of consumers behave, how firms can design products that better fit customer needs, and how marketing activities contribute to shareholder value, among many others (see Roberts et al. 2014).

Strong academic research in marketing can contribute to business school health for several reasons. First, professors that conduct academic research may have greater expertise and, thus, more knowledge to transfer to their students and such knowledge may be fresher as compared to knowledge transferred by professors that do not conduct academic research. Healthy business schools not only teach students skills, but by being academic institutions, also integrate scholarship and thought leadership in the fabric of the institution. The result is alumni who are better managers and who make a larger and more enduring impact on business and society. Second, higher perceived marketing knowledge in the school also may bring better participants to programs. Academic research rankings may signal teaching quality to high-quality prospective students (Besancenot, Faria and Vranceanu 2009). Better-known and influential marketing professors bring in better marketing students who, through social influence and learning, positively affect each other's skills, create a more fruitful pool for recruiters, securing better placements. Third, faculty research may be easily observed by peers and affect the quality perception of such peers of the respective school. External faculty input in review processes of programs and schools as well as the communication by deans with a research background may advocate certain schools based on their academic research (Mitra and Golder 2008). 
Focusing on the marketing field alone, Figure 1 demonstrates our logic of how academic research in marketing may potentially foster business school health. Essentially, academic research in marketing may foster a better perceived knowledge base among marketing professors, which, in turn, may foster the school's impact on professionals in the domain of marketing. Note that we expressly use the term "professionals in the marketing domain" instead of "marketing managers" to recognize the potential relevance of our academic research in marketing to professionals in other organizations beyond companies as well as other functions in firms. However, criticisms in the last decade on the value of academic marketing research, and business school research at large as cited above, seems to indicate that, at this point, the connections in the value chain above seem not perfectly aligned (anymore) and there are limiting factors that could be improved.

First, it seems that the alignment between academic marketing research and perceived marketing knowledge in business schools has an important limiter: the metrics that guide academic research may not steer towards gaining marketing knowledge per se. Therefore, academic research may not contribute as much to the perceived marketing knowledge present in business schools as it potentially could.

Second, it seems that the impact of perceived marketing knowledge in business schools on professionals in the marketing domain has an important limiter: lack of professional alignment between the knowledge generated and the knowledge needed by a sizeable professional audience. Marketing knowledge in business schools may not foster impact on professionals in the marketing domain as much as it could, if it is not the knowledge that professionals value and seek.

Third, the overall chain between academic marketing research and impact on professionals has a third limiter: the incentives that guide academic research in marketing. While academic research should be guided by intrinsic motivation, it is more and more impacted by extrinsic 
motivation such as awards and cash bonuses for publications. Such extrinsic motivation steers academic marketing research in a suboptimal direction and could damage the symbiosis between academic marketing research and business school health as so many have declared in the most recent decade or so with increasing vocal tone, insistence, and publicity. Next, we discuss these limiters, each in turn.

\section{ACADEMIC RESEARCH IN MARKETING AND BUSINESS SCHOOL HEALTH: LIMITERS}

\section{Limiter 1: Metrics}

The most common measures by which business schools or their evaluators assess academic research in marketing are foremost the number of journal-weighted publications and secondary the number of citations. Both measures show strong limitations, especially when used in isolation.

Number of journal-weighted publications

Publications. Scientific publications are official, published, accounts of what a scholar's or group of scholars' ideas are and how those ideas were validated. Typically, they have passed multiple rounds of review, which may come at the expense of the most creative aspects of the research and the passion of the author(s) (Bourdieu 2004). Thus, a journal article is limited in the extent to which it reflects an individual academic author's own knowledge, as compared to knowledge added or altered by co-authors, reviewers and editors.

Journal-weighted. As an improvement of assessing scientific output by the total number of publications, most assessors of scientific publications typically weight by the journals in which the publications appeared. Journals are typically weighted by peer assessment of journals (what we all consider "A's" are "A's") and/or the journal's Clarivate Analytics Web of Science impact factor 
(Clarivate Analytics currently holds all rights to Web of Science, previously held by Thomson Reuters and before by ISI, the Institute for Scientific Information) ${ }^{2}$. The logic is that the best marketing knowledge appears in the premier " $\mathrm{A}$ " marketing journals as they can be the most selective in what content to publish and they receive the highest number of submissions as everyone seeks to publish there. According to this logic, the most frequent contributors to premier journals are regarded as the best academic marketing minds in the world.

However, there are several problems with such weighting of publications. There is considerable variation across schools in what journals are on this list of "A" journals and, depending upon that list, one gets a different ranking of the best academic minds in marketing. The four marketing journals always on this list are the Journal of Marketing Research, the Journal of Marketing, the Journal of Consumer Research, and Marketing Science. Beyond these four, however, there is considerable customization by school. For example, some schools would consider Journal of the Academy of Marketing Science and the Journal of Consumer Psychology as A, because they are on the FT top 50 list. Other schools would regard International Journal of Research in Marketing or Quantitative Marketing and Economics an "A” journal.

Moreover, peer reputation of journals may not match the Impact Factor rankings complicating matters further. Figures 2, 3, and 4 show that leading marketing journals have been losing ground relative to other major business journals in terms of their Impact Factor. The generally accepted "A" marketing journals are not necessarily among the highest impact journals in marketing or business (in general). ${ }^{3}$ Table 1 shows that while the Journal of Marketing is the

\footnotetext{
${ }^{2}$ Some schools now start to use the Article Influence Score (AIS) of journals with the hard-to-substantiate claim that this leads to a level playing field across disciplines and makes disciplines more comparable. Empirically, the use of the AIS score disadvantages fields such as marketing and operations research in favor of disciplines such as finance and economics.

${ }^{3}$ This is similar to the situation in economics as shown in Heckman and Moktan (2018).
} 
second most highly ranked journal in marketing, according to the 2-year Impact Factor, the Journal of Consumer Research, the Journal of Marketing Research, and Marketing Science are only numbers 5, 8, and 14 respectively. This means that assessments based on peer reputation may differ from assessments based on Impact Factor (e.g., rankings of quartiles).

Scholars in marketing also may publish outside marketing and large variation exists across schools on how to count such publications. Other fields such as psychology (e.g., Psychological Science), sociology (e.g., American Journal of Sociology) and economics (e.g., American Economic Review), also have their "A" journals and they are typically counted, but the desired ratio of (marketing publications)/(outside marketing publications) typically varies considerably between schools. On the one hand, a marketing scholar using economic methods may gain reputation from publishing in the American Economic Review. On the other hand, publications in marketing journals may be more visible to a marketing audience than publications in other fields. This has become more of an issue as the number of entry-level faculty with their doctorates from psychology and economics hired by marketing faculties has increased.

Number. A count of publications trades off information for simplicity. Some schools actually tell newly-hired faculty how many publications they need for tenure, often sorted by "A" versus others. Whatever publications assessors decide to count, variance in quality between the publications that are counted is ignored. However, a pure count may lead marketing academics to pursue more short-term projects that pay off with papers which have faster publication times, rather than pursue big ideas that take longer to mature, but fundamentally change the way scholars and/or practitioners think (Bradlow 2008). In essence, academic researchers may merely want to cross the minimum bar in the easiest of the counted journals rather than pursue the highest possible quality that overshoots, hopefully by far, the minimum bar. Also, as assessors typically do not 
discount for number of authors or author order (if they do, the discount is typically small), mere counting rewards "free riding" on papers where the contribution of the $\mathrm{n}^{\text {th }}$ author is questionable. As the number of co-authors in leading marketing journals is on the rise (see Table 2) and the share of single-authored papers in those same journals is in decline (See Figure 5), not properly correcting for the magnitude of contribution in joint work seems increasingly problematic. In essence, there is increasing variance across fields and scholars what merits co-authorship and what does not, and such increased variance risks of completely derailing scientific assessments. One can only hope that hyperprolific scholarship - publishing more than one paper every five days - will be increasingly frowned upon rather than admired and that co-authorship criteria will be implemented with increasing rigidity (see Ioannidis et al. 2018) ${ }^{4}$.

Another implication of counting is the inherent pressure of producing more, which has resulted in science integrity issues such as the use of fake data, cherry-picking, p-hacking, or publishing in fake or predatory journals (i.e., a practice of hundreds of thousands of scientists worldwide according to data of the International Consortium of Investigative Journalists (ICIJ) revealed in July 2018). The irony of this is that in recent years, business schools have placed more emphasis on ethics in their curricula, while now being challenged on the research ethics of its faculty.

\section{Citations}

A secondary often-used measure is the number of citations to the scholarly research of a marketing academic, most commonly derived from the Google Scholar or Web of Science universe

\footnotetext{
${ }^{4}$ Ioannidis, et al. (2018), in their work on hyperprolific authors, adopt the Vancouver citeria established by the International Committee of Medical Journal Editors in 1988, which are: (1) play a part in designing the study or processing the results; (2) help to write or revise the manuscript; (3) approve the published version; (4) take responsibility for the article's full content. Scholars must do all four things to qualify as a co-author on a paper.
} 
(for the differences between the two, see Goldenberg et al. 2010). Many schools today include a mandatory component to the review process which is a comparison of citations to a peer group of scholars. Citations are considered by many as the primary means by which one can measure the intellectual indebtedness of all other scholars across all fields to a specific article or focal scholar (Stremersch et al. 2007). According to this logic, one considers scholars with high intellectual influence on other scholars to possess greater marketing knowledge than scholars with lower intellectual influence.

There are a few problems with this logic that may limit the value of citations as a metric of an academic's marketing knowledge when used in isolation. First, Stremersch et al. (2015) demonstrated only $15 \%$ of all citations to articles in academic marketing journals signal intellectual indebtedness (other fields may show similar patterns). If the majority of all citations can only be explained by citation gaming (e.g., I cite you, you cite me), citation politics (e.g., pleasing potential or effective reviewers), or mere randomness (sometimes referred to as perfunctory citation), it cannot be a very good measure of the marketing knowledge that an academic's research represents.

Second, citations are terrible measures to compare academics on marketing knowledge across domains. Stremersch et al. (2007) shows research domain in marketing to be one of the dominant drivers of citation counts. Reasons include varying popularity, citation traditions and readability across research domains. Thus, citation counts may be an indicator of the research field in which an academic publishes rather than the intrinsic quality of her work.

Third, citations can be increased through extensive social promotion (Merton 1968; Stremersch et al. 2007). If citations are driven substantially by such social promotion, they may be more indicative of the salesmanship of a scholar rather than of the quality of her marketing knowledge. 
Finally, similar to the number of publications, the number of citations is a count variable which by its very nature can fall victim to a quantity concern. Citations accumulate over time and across all possible publications of a scholar, even the lowest of quality, such as predatory journals. Many assessors tend to only look at a scholar's aggregate citation count, rather than to look at the distribution of citations across a scholar's papers and to examine the nature of the highly-cited papers. Were the highly-cited papers of a scholar very original contributions in premier journals or were the highly-cited papers review articles in secondary journals? Has a scholar published premier journal articles that belong to the top $20 \%$ cited papers in a volume or are the scholar's premier journal articles consistently in the bottom $20 \%$ of the respective volume of the journal? In which journals were the top 5 or 10 cited articles (e.g. the first page of Web of Science) of a respective scholar published? Are many of the scholar's Google Scholar cites to textbooks rather than innovative journal contributions? Aggregate citation counts fail to examine such deeper questions that may be informative to an assessment committee.

\section{Limiter 2: Professional Alignment}

A second limiter to the potentially positive impact of academic research in marketing on business school health is the weak professional alignment between much of the knowledge generated from academic research in marketing and the knowledge that would be valued and needed by a professional audience. From previously cited research, this appears not to be a new problem (Reibstein et al. 2009), but one that has worsened significantly over the last decade.

Most marketing academics accept that the translation of academic knowledge to practical application may be a long diffusion process (Roberts et al. 2014) which is common to many science fields (Rynes et al. 2001). Such slow diffusion speed may be even what distinguishes fundamental research from applied research. However, the limiter we identify is not a lengthy diffusion process, 
but irrelevance, in both short and long term, of a too large body of knowledge generated by academic marketing research to a professional audience. In the words of Shapiro et al. (2007), we perceive the limiter to be in the production of knowledge, not in the translation thereof.

Marketing academia has already undertaken quite a few steps to make its academic research more accessible to practitioners. Many premier journals (e.g., Journal of Consumer Research, Journal of Marketing, and Marketing Science) have improved their accessibility to professionals by translating the research they publish in a journalistic style. Some of our leading journals have established practice prizes, such as the Gary L. Lilien ISMS-MSI Practice Prize, embedded in the INFORMS Marketing Science community or the MSI H. Paul Root Award for the paper with the highest managerial relevance in Journal of Marketing. Organizations such as MSI and ISBM continue their quest to bridge academia and practice, organizing joint meetings, workshops and conferences. Despite these significantly increased efforts to prevent academic research from being lost in translation, critique on the managerial relevance of academic research in marketing has only increased in the last decade.

We believe there are several reasons why the alignment between the production of academic marketing knowledge and what knowledge professionals in the marketing domain value are at odds. A first reason, quite ironically given the "bashing" on publication metrics under limiter 1 , is the absence of or lack of valuation of metrics on publications specifically targeted to a professional audience. Publishing in practitioner-oriented journals receives little weight at today's research-oriented business schools. For instance, while a publication in Harvard Business Review reaches many more people than a paper in a top academic journal ( $H B R$ has a circulation of over 260,000) and has positive benefits for a marketing scholar and his/her institution, such a paper typically counts zero towards promotion in research-intensive institutions. Such publications 
would also enable marketing academics to develop knowledge on complex phenomena in a more holistic manner than enabled by the scientific approach, which requires scholars to dissect a complex problem into isolated small sub-problems. Other fields also have so-called "bridge" journals that are highly respected, e.g., for Finance these are the Financial Analysts Journal and the Journal of Portfolio Management. INFORMS, the parent organization for operations research/management science academics (including marketing scientists) publishes two such bridge journals, OR/MS Today and Interfaces. Marketing has none.

A second reason, especially relevant when one compares Marketing to Finance, may be that marketing "management" decisions are surrounded with more ambiguity than financial decisions. Following the logic implied by Bennis and O'Toole (2005), one could consider Finance as more related to Economics, which is characterized more by the scientific approach to welldefined problems (i.e., small problems can be easily and meaningfully isolated to the level required for scientific inquiry). Marketing may belong in its core more to Management, which befits more the professional approach to highly ambiguous problems (i.e., by scientific isolation the knowledge generated may lose practical meaning). Thus, with the justified science-switch of business schools to more rigor, Marketing has had a bigger challenge marrying rigor with relevance in comparison to Finance. As a result, we have seen the gradually decreasing presence in our premier journals of marketing management topics higher in ambiguity such as marketing organization and strategy. Its demise has left the marketing field bifurcated between modeling and consumer behavior (Reibstein et al. 2009). Both latter subfields of marketing seem to have a more specialist audience also among specialist practitioners than what before was known as marketing management or marketing strategy. As a result, we more commonly observe managerially relevant knowledge 
based on academic research that solves small, immediate, problems rather than long-term, big problems (Webster and Lusch 2013).

A third reason was the entry over the last 2-3 decades into our field of well-trained economists, econometricians, statisticians and psychologists (Roberts et al. 2014). They were welcomed because they brought hard skills and the scientific method (with a subsequent increase in reliability and validity) that many marketing academicians lacked. However, their focus remains often devoted to the source discipline and the scientific sophistication it may bring to marketing at the expense of attention to professionally relevant answers to important marketing problems (Lehmann, et al. 2011). In economics, Akerlof (2018) has termed this the "hardness" bias, in which scholars (in his case, economists) may put more weight on hardness (i.e., precision) and less weight on importance in selecting research topics than is socially optimal, leading them to ignore important topics. The influx of "hard" scientists has steered knowledge development in a direction not necessarily concordant with the interests of a wide audience of professionals in the marketing domain, but instead in a direction concordant with specialized scientific interest. Also, the search for reliable and valid new methods and new theories, which, ideally, should stand the test of time, does not allow to shrink the total time a paper at our premier journals (who work hard to keep turnaround times as low as they possibly can) typically spends between idea conception and ultimate publication-in-advance. However, practice - both society in general as well as professional interests - evolves at an ever-faster pace and in that sense simply is destined to outpace the science model.

Fourth, practically coinciding with, but seemingly not caused by, the entry of well-trained specialists in source disciplines, practitioners disappeared out of the review and readership loop. It is interesting to note the changes in the compositions of the editorial boards of three of the 
leading marketing journals since their inception. From Table 3, it can be seen that the early days of JMR, JCR, and Marketing Science showed some representation of practitioners on the editorial board. However, today, there are zero. Conferences have gone the same way. The first Marketing Science Conference in 1979 sought a 50/50 split of academics and practitioners, 11 out of 40 papers in the conference proceedings were by practitioners and many practitioners were on panels (Wittink 2001). Today, it is rare to run into professionals at Marketing Science conferences or ACR (AMA conferences are a special case as the predominantly academic conferences are even labeled "Educators' Conferences"). Figure 6 shows the evolution in the practitioner participation in the Marketing Science Conference since 2005, which has further decreased to only 3\% of the total number of attendees in the last three years ${ }^{5}$. From our discussions in the context of this project with colleagues in Finance, we learned that finance conferences routinely include people from investment banks and other financial institutions. Also, people from investment banks and financial institutions are also more routinely affiliated with a university as an academic, not as an adjunct (which would be the common way this would be done in marketing), but as research-active faculty.

\section{Limiter 3: Incentives}

Our third limiter is the incentive system a business school designs and in which marketing academics develop their research. Today's academic incentive system in research-oriented business schools has several components.

A first incentive is the granting of tenure, typically based on a mix of performance in teaching, research and service, of which the research component weighs most heavily. The

\footnotetext{
${ }^{5}$ We acknowledge the kind assistance of Doug Bowman, who provided us with the source data since 2005, and one of our PhD students to code the raw data in academic - practitioner participants.
} 
research component in tenure decisions is highly dependent upon the number of journal-weighted (preferably "A"-level only) publications, possibly complemented by comparative citation counts as noted above. Many European business schools have now solidly adopted this practice also (Besancenot, Faria, and Vranceanu 2009). These publication and citation counts are normally complemented by letters from an external group of scholars who are asked to review the record of the candidate. In leading U.S. schools, it is customary that this reference group is completely independent from the candidate, while in many non-leading and European schools the reference group routinely includes "friends and family" of the candidate including, for example, co-authors.

Minimally, opinions on the candidate's research record are sought. Often, opinions on the other two dimensions of evaluation, teaching and professional/school service are also requested. There is large variance in the instructions and data provided for the external letter writers. Invariably, the letter writers are asked to compare the candidate to his/her peers, but with few exceptions, no comparison list is provided. Two issues emerge with this process. First, while it seems natural to choose external evaluators on the basis of similarity of research domains, this approach eliminates the opportunity to get a broader perspective on the candidate's research. It is also likely that the resulting opinions on the work are based on an established set of norms, as well as possibly social relationships, in that particular domain which could either work for or against the candidate. Second, the lack of specific instructions about what items to cover in the letter results in heterogeneous and idiosyncratic evaluations of the candidate, particularly since letter writers generally do not pay much attention to the dean's invitation and do what they normally do. In particular, the lack of a specific comparison set puts the burden on the letter writer to figure out who received a doctorate roughly in the year the candidate did with no complete database of such 
information. Since few outside evaluators will put the time into determining who graduated when, the resulting comparisons are often wildly off base in terms of the true cohort.

A second incentive is salary. Our current salary system is a limiter for two main reasons. First, the number of journal-weighted publications - a limiting metric as identified before - is by far the strongest and in many cases the sole research determinant of salary (increases). Mittal et al. (2008) find that publications in the premier marketing journals lift salary with more than $\$ 2,000$. They also find variation among such journals with Marketing Science $(+\$ 4,130.78)$ and Journal of Marketing (+ \$2,688.05), leading to higher salary increases than Journal of Marketing Research and Journal of Consumer Research. The high salary return on a Marketing Science publication likely originates from the relative scarcity of marketing modelers in the field, while that of Journal of Marketing may originate in its stature as the discipline's "biggest tent" and high impact factor (Moorman et al. 2018).

Second, salaries in many schools are high and have steadily increased in the recent years. Figure 7 shows the salary increases for "rookie" assistant professors in marketing, according to the three subdomains in marketing (Consumer Behavior (CB) - Marketing Strategy - Marketing Modeling). Again, one clearly notices also in this data, the substantial salary premium for marketing modelers, which seems to have even further increased in the observation period (in 2017 , the average "rookie" marketing modeler received a total salary of $\$ 221,716$, while consumer behavior and marketing strategy scholars received on average less than $\$ 140,000)^{6}$. While salary increased more or less at par with U.S. inflation in the period 2004-2007 (3.08\% versus 3.03\%) and the period $2008-2012$ (1.70\% versus $2.06 \%)$, it substantially outpaced U.S. inflation in the

\footnotetext{
${ }^{6}$ Salary information presented here is based on AMA DocSig's annual "Who Went Where? Survey Report.", which is based on an elaborate survey of all rookie Assistant Professors in Marketing. In 2017, for example, 52 rookie professors provided salary and placement information. Only placements in the US are used for the salary analysis.
} 
period 2013-2017 (3.09\% versus 1.32\%). Salaries at research-intense schools outpaced U.S. inflation even more so, by almost $4 \%$-points (5.21\% versus $1.32 \%)$. From AACSB data for marketing professors (see Figure 8), we learn that the career trajectory is to start on a, historically speaking, high salary as a rookie (the AACSB data show a similar growth trajectory as the AMA DocSig data), with a pretty flat salary curve at first at assistant and associate levels (given tenure may be the main reward, i.e., securing a high salary for life), with then again steeper salary increases at the full level. While in the past, marketing professors needed consulting to complement their academic pay check, they can live prosperously from their research today without ever setting foot in a company (Lilien 2011). In this manner, academics are less exposed to the timely needs of professionals for marketing knowledge.

A third incentive that was introduced more recently are publication bonuses. This practice was first introduced presumably (at least, this is where we first heard about it several years ago) in Norway, where scholars can receive a salary bonus of anywhere between 30,000 NOK to 400,000 NOK or more per article published ${ }^{7}$. This practice of salary bonuses directly related to the number of publications is now also adopted in China, France, and Portugal, among others. In France, a typical practice is that professors in private business schools receive approximately $€ 15,000$ in salary bonus for a category 1-publication, $€ 8,000$ for a category 2-publication, $€ 2,000$ for a category 3-publication, $€ 1,500$ for a category 4-publication, either defined according to the French research organization CRNS or the own school. In Portugal, professors in some private institutions (e.g., Católica Lisbon) receive both general salary supplements (which they lose if they do not

\footnotetext{
${ }^{7}$ The precise amounts vary across schools, fields, number of co-authors and journal tiers (different tiers lead to different bonuses). Scholars at Stavanger University receive up to 30,000 NOK for a premier journal article. At BI this amount is up to 200,000 NOK (single-authored paper). In Finance, Norges Bank awards up to 400,000 NOK for premier finance journal publications by scholars affiliated with a Norwegian university (see https://www.nbim.no/en/investments/research/the-norwegian-finance-initiative-nfi/nfi-publication-bonus/). 1 NOK is equal to $\$ 0.12$ (exchange rate in October 2018).
} 
publish enough papers of a certain level) as well as individual salary bonuses per premier journal publication. Such bonuses are also common in many Chinese business schools. Some schools in the U.S. give such bonuses in the form of additional research money, rather than in the form of a salary bonus.

From the above, it is clear that in their transition towards the research model, business schools have increased extrinsic rewards for academics to do research (i.e., steeper salaries and newly introduced salary bonuses), at the risk of crowding out intrinsic motivation. Although formal evidence is lacking, one may wonder to what extent tenure today serves intrinsic motivations, such as enabling more academic freedom and risky innovation post-tenure, or more extrinsic motivations, such as economic job and income security. In economics, Brogaard et al. (2018) have shown that both quantity and quality of research peak at tenure and fall thereafter.

Prior literature on motivation in economics (e.g., Frey 1997) and psychology (e.g., Deci 1971) has pointed to several risks of increasing extrinsic rewards that may be relevant in understanding how incentives limit the extent to which academic research in marketing may contribute to business school health, of which the three most noteworthy in our context are probably as follows.

A first risk is that the extrinsic reward detracts academic researchers' attention from the process of task activity (i.e., knowledge generation and diffusion) to the product of getting a reward (i.e., getting a bonus or a salary increase for an additional premier journal article). Extrinsic rewards alter goal-proximity, from task-focused to outcome-focused (Condry and Chambers 1978; Bénabou and Tirole 2003). In other words, extrinsic rewards trigger people to see a task as the "means" to achieve the reward, rather than an end in itself. In sum, increased extrinsic rewards 
may limit the degree to which academic research in marketing contributes to perceived marketing knowledge in business schools.

A second risk relates to the interference of extrinsic rewards with one's competitive versus cooperative orientation. Extrinsic motivation leads people to emphasize personal rewards such as money, appearance or social recognition at the expense of "higher level" goals such as affiliation, self-acceptance and community feelings (Kasser and Ryan 2001). Extrinsic rewards may trigger academic researchers to adopt motivations that depart from what Haack (1997) calls genuine inquiry and are closer to motivations that she associates with fake and sham inquirers. The genuine inquirer seeks to find the truth, not to become rich, famous or popular. The sham inquirer merely seeks to make a case for an immovably-held preconceived conviction. A fake inquirer is only interested to advance himself by making a case for some proposition to the truth-value of which he is indifferent. Such non-genuine inquirers befit a Machiavellian view of scientists' strategies, which Bourdieu (2004) calls influence- and power-seeking in the pursuit of self-glorification. As genuine inquiry in marketing will fuel the best marketing knowledge and the highest impact on professionals in the marketing domain, increased extrinsic motivation may act as a limiter to the potential influence of academic research in marketing on business school health.

A third risk relates to the interference of extrinsic rewards with one's creativity. Research in psychology shows that people make optimal use of their creative skills when "they feel motivated primarily by the interest, satisfaction, and challenge of the work itself" instead of external rewards or punishments (Amabile 1998; p. 79). This happens because intrinsic motivation triggers more cognitive flexibility than extrinsic motivation, leading people to adopt a more exploratory mindset (Amabile 1993; McGraw 1978). In contrast, extrinsic motivation leads people to adopt a more "algorithmic" mindset which does not allow for exploration and, instead, focuses 
attention on relatively straightforward aspects of performance, such as sheer technical quality (Amabile 1993). Thus, extrinsic rewards may lead academic researchers to focus more on less creative and potentially narrower aspects of their work - such as methodological sophistication at the expense of more creative but also potentially broader aspects of their work, such as novelty and usefulness. In turn, the narrowness in academic research that extrinsic rewards may trigger may limit the extent of new marketing knowledge development and the usefulness of such knowledge to professionals in the marketing domain.

\section{RECOMMENDED IMPROVEMENTS}

Now that we have described the limiters of academic research in marketing, we can address how to improve the contribution of research in marketing to business school health. In our minds, what is desired is improving our current system to shift the above limiters, not a complete overhaul of the fundamental ways in which we have increased rigor of academic research in marketing over the last decades. We have aimed to identify improvements that can have a substantial impact, but also to which all like-minded academics can contribute to in the various roles they fulfill on the faculty of business schools, be it as department head, member of the P\&T (Promotion \& Tenure) committee, (associate) dean or informal influencer of the business school system.

\section{Improvement 1: Supplementing Quantitative Metrics with Qualitative Metrics}

Quantitative metrics, such as number of premier journal publications and citation counts, are here to stay. They permit the categorization of academic researchers into broad categories such as unproductive or non-influential, moderately productive/influential and very productive/influential. However, as we have argued above, at times, they provide limited or 
possibly misleading information. Also, when used exclusively, they promote unscholarly behaviors among academics. Therefore, rather than building optimization engines based on automated top journal and citations counts as proposed by Bertsimas et al. (2015), we need to more effectively supplement quantitative metrics with qualitative metrics.

\section{What to measure?}

In general, we advocate more reading and evaluating than counting. While assessors normally read the papers of candidates, the goal is often more to summarize the research than to perform an in-depth perspective on the work. Several qualitative metrics that show promise are: (1) creativity; (2) novelty; and (3) literacy. In a number of other fields (think of fine arts, theater, and architecture), it is not unusual for the creativity of a person's research to be a key criterion, even more important than publications, for promotion or appointment. A scan of the promotion criteria at a number of these departments at New York University prominently features creativity. For example, in both the Tisch School of the Arts and the Steinhardt School, evaluation of a candidate's creative activity are important dimensions of a candidate's record. There is an extensive literature on creativity with well-developed and reliable measurement procedures which enables creativity assessment through a panel of independent experts (Amabile 1982; Besemer and O’Quin 1986).

Other scholars have developed approaches for measuring the novelty of research - one of the sub-dimensions of creativity - using bibliometric methods which allows them to be automated. For example, Wang et al. (2017) measures the novelty of a paper by examining the variation across disciplines in its reference list. Using this measure, they find that highly novel papers are highlycited, inspire follow-on highly-cited research, and are more likely to be cited in disciplines outside of the "home" field. 
While creativity or novelty in academic writing would measure to what extent a thought leader is likely to inspire, a professor's literacy would measure the knowledge base s/he can rely on. Reading what others publish is an essential part of research and is an important way in which knowledge can be gained. Still, such reading today is not incentivized and finds no reward. Even more, as there is a time tradeoff between reading and writing (when one is reading, one cannot write and vice versa), the system seems to discourage reading as it excessively rewards writing. Besancenot, Huynh and Vranceanu (2009) show that as the rewards for academics for writing go up, the total number of papers written increases, and the time researchers can spend on reading goes down; as a consequence, the quality of research is depreciating. Consistent with poor time allocation to reading, several scholars in marketing have found poor citation practices (Stremersch et al. 2015).

\section{How to use these measures?}

Qualitative measures such as those above can supplement quantity-based measures such as publications or citations in various assessments of scholarly research and add richness and depth to the faculty evaluation process, such as the P\&T process. We do not believe schools need to change the P\&T committee composition, nor the way in which it advises the university at large on P\&T matters. The essential change that in our mind is needed is in the solicitation of outside reference letters and the assessment criteria used.

As argued above, the solicitation of outside reference letters is imperfect. Large variance exists in the instructions and data provided to the external letter writers. The school typically does 
not provide a cohort list ${ }^{8}$, nor does it provide a clear set of metrics or tasks on which the evaluation is based. It is not uncommon (one of the authors recently saw such a letter) for an external reviewer to note something like "Since you did not give me explicit guidelines as to what to consider ...." Consequently, letter writers may resort to the well-accepted quantity-based metrics for cohort comparison, but with varying definitions of the cohort, or provide some qualitative input, which is not comparable across letter writers and is therefore difficult to integrate into P\&T discussions. As a result, P\&T committees may resort (again) to purely quantity-based measures. One may also wonder whether senior scholars from the domain of the evaluated academic are the most appropriate if one would like to include measures such as creativity, novelty, and literacy in their assessment. It seems that many of the limiting factors we discussed above are kept in place because they may be self-serving to a well-connected inner crowd.

We propose that marketing scholars in their schools use their influence in the P\&T process for their respective departments to (1) nominate a heterogenous set of letter writers, rather than nominating a rather homogenous set of letter writers, and (2) create a much clearer briefing to external letter writers with an explicit list of the metrics they would like letter writers to use such as those in Table 4 rather than allow the letter writers to use metrics idiosyncratically. Figure 9 captures this recommended change in process. A heterogenous set of letter writers should definitely include former or present (area) editors of journals of which the candidate has been on the Editorial Review Board (ERB), as well as established scholars across the infamous silos consumer behavior, strategy and modeling.

\footnotetext{
${ }^{8}$ Many schools are perfectly capable of doing this already since it is becoming more common for a cohort list to be developed for internal purposes. We do recognize, however, the possibility of "gaming" the list provided to the external reviewers.
} 
One may even think to solicit opinions from professionals in the marketing domain. While this may sound like it is a radical idea, it is not. For example, the Tisch School of the Arts forms its external review committees using academics as well as someone from the performing arts community. In Table 4, we also propose a template based on the measures above that could be used to offer better guidance to letter writers, although obviously metrics can also be offered in the solicitation letter. We also propose to include a clear set of scholars of the same cohort as the candidate. This recommendation befits an increasing trend to generate such cohorts top-down for internal school use or bottom-up by cohorts of scholars to make their tenure pack more evidencebased (see www.perceptionstudies.com/docsig2013 for an example).

In Table 4, we sort the assessment by quantitative and qualitative criteria. Our proposal is that roughly one-third of the assessment be devoted to the number of journal articles, citations and the qualitative measures. Depending upon the school, different data combination rules can be employed. A school that wishes a candidate to have strength in all areas can use a compensatory model. Schools where more strength is desired in the number of top publications can use a noncompensatory rule. Our key recommendation is that the creativity, novelty, and literacy of the work be added to the evaluation process, to uncover what may go unnoticed in a purely quantitative assessment.

The input one would obtain following this process would be, in our mind, an effective way in which to supplement quantity with quality. Of course, alternative solutions exist. For instance, one best practice we encountered in our research for the present article is a school that asks of a candidate to list her/his best five papers. Consequently, only those five papers are considered in the P\&T process. With a reduced and more focused set of work to consider, this would facilitate P\&T members reading the respective papers more carefully and comparing across candidates 
much more qualitatively. This is an alternate way in which one can counterbalance quantitative with qualitative input, which is the main thrust of our plea. It is also complementary to the template in Table 4, which could be upgraded with a comparison of the best 5 papers of the candidate compared to the best 5 papers of the respective cohort. It also befits our own beliefs that schools need to continue to set a lower bound to the number of premier journal articles a candidate needs to have published as a necessary, but not sufficient, condition, before s/he can be promoted or tenured.

Along similar lines, we believe assessors need to devote more attention to merely aggregating citations across all publications of a candidate. Assessors and external reference letter writers can be asked to assess citations quantitatively but with an eye for the distribution of citations across papers and paper types, rather than merely using the aggregate total count in their assessment. The first page of the citation report - ranking publications on the number of citations - can be obtained from Web of Science. It is a key metric to evaluate citations quantitatively in a format such as Table 4. For external letter writers, schools could conveniently include the first page of such Web of Science citation report of the candidate as well as for the cohort comparison group for evaluation. To produce the best research in Marketing that is possible, we need to escape from the mere numbers culture that pervades today.

\section{Improvement 2: Socialize Marketing Academics Into Practice}

As our limiter analysis of professional alignment revealed, academic research in marketing today is too distant from the profession. Our discipline has attracted talented individuals from economics and psychology that have brought rigor but little institutional knowledge and perhaps interest in the practice of marketing. At the same time, we are searching for ways to inform professionals, who face high ambiguity in decision-making, about academic advances in marketing 
that could help them. And as we have noted previously, in the transition to the scientific research model, our field has lost its following among professionals that can bridge the two worlds. Therefore, we consider as a second improvement to better socialize marketing academics into practice.

In our research for the present paper, we were particularly inspired by the field of Finance and wondered whether their model could be emulated by marketing. Two particular ideas come to mind. Marketing needs to have a "bridge" journal. It would not be difficult to find a group of senior scholars who are motivated in this direction. It could come under the umbrella of AMA or INFORMS, both of which are interested in academia and practice and modeled after, say, Interfaces. Refraining from suggesting a named list, one can imagine such academics could be sourced among the senior scholars who head a research center, organize an initiative in which firms partake, have advocated themselves for a tighter link with practice, organized practiceacademia fora, are well-known thought leaders for practice, or are engaged in senior-level consulting. This new journal would deliver a specialized outlet rather than trying to reinstate practitioners in our leading premier journals which could negatively affect some of the gains we have made in the recent decades in increasing their scientific status.

One may also wonder, if such journal could be founded, if there would be enough momentum to establish a number of parallel "bridging" tracks in conferences such as the INFORMS Marketing Science Conference or the AMA Winter Educators' Conference. This could go hand-in-hand with upgrading the missions of many of the AMA's 17 Special Interest Groups or SIGs to fostering relationships between AMA's academic and practitioner communities; now, only two, Entrepreneurial Marketing and Innovation, Technology and Interactivity have missions that seek to achieve this. For the Marketing Science Conference, it may be worthwhile to re- 
introduce a desired balance between academics and practitioners in line with the original intent as expressed by Wittink (2001). One way in which this could be accomplished is in making the central part of the conference a hotspot for sessions that balance academia and practice. This would bring a real-life socialization platform for junior scholars to connect with relevant professionals in their domain.

Also business schools' leadership could stimulate such academic-professional alignment. Business schools have, in many cases, actively discouraged consulting as a side activity of its faculty. At the same time, many faculty members in Finance have either founded or become "quants" in financial services firms. While discouraging consulting has brought short term gains in schools' research productivity, it has brought long-term losses in impact among professional stakeholders. Roberts et al. (2014) examined 20 top dual-impact papers in premier marketing journals and found such papers to be born out of symbiosis with consulting and often co-authored by a senior scholar with strong practice experience. Therefore, we recommend that schools encourage their senior faculty to engage more with practitioners such as through consulting or expert witness work while maintaining the "rigorous research only" incentives for junior faculty. The transition moments from junior to senior should enable the bridging of both in strong research teams that combine methodological sophistication with senior-level insights into problems of the profession at the moment when the junior faculty member is socialized into a more senior role.

There are a number of other initiatives that could be taken by schools to enhance the relationships faculty have with practice. First, faculty could be encouraged to give talks in companies. We have done this a number of times and the two-way transfer of knowledge is considerable. Second, almost all research-oriented business schools have invited speaker series. This presents an opportunity to invite a researcher from, say, Microsoft Research or a practitioner 
from a local company to discuss current marketing issues facing them. Third, faculty should not be discouraged from spending parts of their sabbaticals or taking an unpaid leave in a company (so-called externships) where there would be a significant opportunity to enhance the scholar's research through either access to data or observation of problems that need to be solved (Brower and Steward 2015).

All of this requires that schools and departments need to be more explicit on expectations across a scholar's life cycle. It also means department chairs and deans should be more tolerant of senior faculty engaging in relationships with practice. One of the more interesting cases we discovered is of a school that inventories faculty's consulting assignments, not to prevent them, but to seek how to best exploit them. A senior faculty member's consulting clients may offer opportunities to develop business schools' custom program business or institutional relationships. Moreover, they form opportunities to let junior faculty, often void of practical experience, gain professional insights from being moderately involved in said consulting collaborations. MIT's model of commercializing marketing modeling break-throughs (e.g., Little, Hauser, Urban) and the way it has become a platform for successful dual impact work is legendary. At least three of the 20 top dual-impact papers that Roberts et al. (2014) identified were born out of this MIT model. Increasing opportunities for faculty to earn income would also reduce the pressure schools feel to continuously keep on increasing faculty salaries.

\section{Improvement 3: Strengthen Intrinsic Rewards and Limit Extrinsic Rewards}

In our limiter analysis, we posited that marketing academia is at risk of extrinsic rewards crowding out intrinsic motivation; we also identified the main negative consequences thereof. The above improvements will address some of these consequences in part. Under Improvement 1, we suggested changes to the $\mathrm{P} \& \mathrm{~T}$ process that will temper the mere extrinsically motivated chasing 
of premier journal articles. We also suggested accounting for creativity as a supplement to quantity-based metrics thus reducing one of the main risks of the crowding out effect. Under Improvement 2, we suggested being more accepting of faculty consulting activities which can form a counterweight to salary dependency. However, we feel more could be done specifically focused on strengthening intrinsic rewards and limiting extrinsic rewards.

To inspire the strengthening of intrinsic rewards, one can point to recommendations that flow from the, in marketing well-cited, self-determination theory (Ryan and Deci 2000). This theory posits that main determinants of intrinsic motivation are autonomy (a feeling of control over one's own choices and actions), competence (a feeling that one has the necessary ability to conduct a task) and relatedness (a feeling of belongingness and connectedness to one's peers).

An example of autonomy is that business schools could enable greater freedom in the research projects a scholar wants to embark upon by making bigger financial commitments to research support. The typical business school spends a small fortune on faculty salaries and significantly less on research budgets. While we cited salaries in the order of magnitude of \$150220,000 for rookie faculty above, those same faculty typically need to scramble for $\$ 5-10,000$ in research budgets. In companies, we typically see the opposite where R\&D associates work with budgets that are $\mathrm{x}$ multiples of their own salaries. Which type of organization will attract the best and most intrinsically motivated R\&D talent? An organization that offers high salaries, but limited research funds, or an organization that offers moderate salaries, but unlimited research funds? Professors that guide contract negotiations with new faculty at schools and departments could make up a salary shortfall relative to a competing school (extrinsic motivator) with additional research funds (intrinsic motivator). Equally important is that research funds flow to the most appropriate faculty according to the quantitative and qualitative metrics we have defined above. 
Intrinsic motivation, particularly for senior scholars, can be enhanced by business schools' human resource systems that permit the selection of dynamic "weights" placed on research, teaching, and service. As academics move along the career life cycle, many feel they can make more contributions to a business school through teaching, executive education, or service. Business schools need a mix of faculty types to be successful, that is, they need a portfolio of skills. When empowered to make such career choices, senior faculty members can both enrich their careers, increase intrinsic motivation and contribute to the health of their school.

An example of competence is to strengthen our doctoral programs beyond the focus on methods where we have greatly advanced in the last two decades. One could say that the current training that doctoral students receive may not always be very intellectual as it focuses on core methods for the chosen field, courses in the own field and courses in the source discipline. The focus on methodology creates an increased narrowness in research and a concomitant decrease in the potential for the research to impact practice. There is virtually no consideration of the historical roots of the marketing field and zero socialization with professionals. We propose that marketing doctoral education should include: (1) a course in the history or philosophy of science; (2) a course in the history of marketing thought; and (3) a course in creativity. Doctoral programs should also include practitioners in their pro-seminars and stimulate company internships. Students could also be encouraged to develop a presentation of their dissertation that they would use for a group of company managers or for an MSI or ISBM talk to get them to relate their research to practice.

An example of relatedness is to stimulate more teamwork among faculty in business schools. Innovation research has shown teams to outperform individuals (Singh and Fleming 2010). Still, business schools for the last decades manage their faculty on a rather individual basis, rather than on a team basis. Combined with extrinsic rewards, this management practice risks 
instilling a competitive rather than collaborative department culture (Kasser and Ryan 2001). Culturally embedding expectations on within-department collaboration and fostering them over scholars' life cycle may act as a counterweight. Of course, the optimal balance between external and internal collaborations and the types of collaborations will vary across schools, but greater cohesion may strengthen the intrinsic motivation of scholars to engage in meaningful research. It also enables a better assessment of faculty for promotion and tenure when senior colleagues can assess from direct collaboration experience how much of an expert a younger colleague really is (i.e., does the person match the written record?). Some schools also increasingly recognize that within-department collaboration acts as a safeguard to scientific integrity threats.

We have kept our most radical improvement recommendation until last. This addresses the rising trend of giving faculty salary bonuses for articles appearing in a certain set of journals independent of their intrinsic quality. Of course, we are not against performance bonuses per se. In fact, $R \& D$ workers that have been able to make key breakthroughs are, at times, rewarded by their respective employers with a small share of the firm profits from the respective breakthroughs. However, there is typically a direct link between the breakthrough and the respective R\&D worker, the breakthrough is typically sizeable, and the share is typically small. One can wonder to what extent a salary bonus of several tens of thousands of dollars is reasonable for one academic article in a premier business journal. What if firms would start to pay bonuses for every patent being filed and granted? Would they not incentivize a large stream of potentially meaningless patents, much like bonuses in academia may fuel a stream of potentially meaningless major journal articles? If bonuses must be paid, they should focus on providing additional research funds and not salary.

Therefore, our last recommendation is that senior and leading scholars in systems with bonuses should start to refuse such bonuses for ethical reasons or wire them to a collaborative fund 
from which research grants can be awarded to young scholars. Alternatively, if the system is unavoidable at the individual level (e.g., some universities are considering to supplement fixed pay with bonus pay), senior and leading scholars should speak out against such systems in- and outside their respective schools. At the very least, the bonus system should initiate a strong debate within the field on what could be better ways to intrinsically reward outstanding scholarship.

\section{CONCLUSION}

In this paper, we have attempted to summarize our thoughts on (1) the strong contribution academic research in marketing may potentially have to business school health, (2) the three main factors that limit such influence; (3) the three main improvements that we can bring to shift such limiters. There are, of course, limitations to these recommendations. First, there are always issues of implementation. We are not naïve to think that implementing the above improvements is going to be straightforward (even though at times we made it sound as such). The easiest to implement is the second recommendation, improved socialization of marketing academics with business. These are under the control of either the business schools or individuals. Changing the nature of the academic promotion and tenure process involves the university leadership as such changes cannot generally be made by an individual unit. However, some of the recommendations such as focusing more on reading work rather than merely counting publications or citations can be implemented without the approval of anyone outside the business school. Our call to either eliminate or at least significantly reduce external salary incentives can also easily be implemented but can serve as a differentiator for a school in the worldwide search for academic talent.

Second, readers may feel we have not gone far enough in our search for improvements. An intriguing omission from our Figure 1 is a feedback loop from impact on professionals in the domain to academic research. In an "ideal-world" business school that achieves perfect alignment 
between its academic research in marketing and impact on professionals, one would expect such impact to feedback into future academic research. Such a feedback loop is key in future valorization strategies business schools may develop, which are already standard practice in, for instance, the exact or medical sciences, where firms directly buy into leading-edge research (output). Business schools, for now, do not seem to succeed with such a model and are restrained to models such as sponsored chairs, research centers, research for practice unrelated to premier journal outcomes, or roundtables. We regard the conceptual development of such valorization models for business schools important for their future health and, thus, future research that develops a vision thereon as very promising, but outside the scope of the present paper that focuses on faculty management system improvements.

Third, the present paper takes an assessor's perspective while touching upon a scholar's motivation. In this manner, we feel it generates a useful research agenda for studies on scholarly motivations which is an area which has not seen much interest in scientometrics. For instance, as we noted above, our elaborations on metrics clearly indicate a scholar's potential balancing act between quality and quantity, reading and writing, or premier journal publications and citations. How do or should scholars balance these dimensions of scholarly output? How does this depend upon their motivations? What are the negative consequences of motivations that are seen by some as bad? For a scholar? For the research domain they belong to? Similar questions can be posed when it concerns managerial alignment, as in principle, it is a time allocation problem.

Fourth, the paper lacks a research agenda for marketing. If the reader goes along with our arguments regarding the search for quality, novelty, and creativity instead of quantity or with our arguments on professional alignment, what does it mean for scholars' research agenda setting? How should they set a research agenda? How should they manage their pipeline of projects? What 
is a good or bad way to do this and why? What does it mean in terms of research topics? Is it conceivable to make a list of research topics where the ideal world would be more achievable, while in other topics this would be more complex? For instance, the recent emphasis in many schools on analytics plays directly into what Chief Marketing Officers feel is a critical area of need going forward. For example, results from the 2018 CMO Survey predict a tripling of spending on analytics in the next 3 years (CMO Survey, August 2018). Does this mean that research in these areas will more likely contribute to the general knowledge base of a business school and, as a result, its future health, than other research areas. Are there other research areas that show similar promise?

When qualifying these shortcomings, in line with the call of Yadav (2010), it is important to recognize that we have attempted to write a purely conceptual paper. In such papers, the boundaries where the paper starts and stops are always in part subjective. We considered the faculty management perspective we adopted to provide such bounds at least to some extent. Also, despite their support with some data, we concede all of our claims lack strong proof. We regard providing such proof beyond the scope of the paper. It would obviously be beneficial if future research would provide it, but it seems a daunting task that again may prove to be "too little, too late" once it is executed and reviewed. However, an important goal of any conceptual paper is to stimulate further discussion, both formal and informal. We hope that this paper succeeds in doing so. 
Table 1:

Ranking of Marketing Journals According to Journal Impact Factors

\begin{tabular}{|l|c|c|}
\hline Journal Name & $\begin{array}{c}\text { Rank in } \\
\text { Marketing }\end{array}$ & $\begin{array}{c}\text { Rank in } \\
\text { Business }\end{array}$ \\
\hline Journal of the Academy of Marketing Science (JAMS) & 1 & 5 \\
\hline Journal of Marketing (JM) & 2 & 9 \\
\hline Journal of Interactive Marketing & 3 & 10 \\
\hline International Journal of Electronic Commerce & 4 & 18 \\
\hline Journal of Consumer Research (JCR) & 5 & 19 \\
\hline Journal of Retailing & 6 & 20 \\
\hline Journal of International Marketing & 7 & 23 \\
\hline Journal of Marketing Research (JMR) & 8 & 25 \\
\hline Journal of Consumer Psychology (JCP) & 9 & 29 \\
\hline Industrial Marketing Management & 10 & 33 \\
\hline Journal of Advertising & 11 & 38 \\
\hline Marketing Theory & 12 & 43 \\
\hline International Journal of Advertising & 13 & 47 \\
\hline Marketing Science (MKS) & 14 & 56 \\
\hline
\end{tabular}

Source: Web of Science (accessed January 2018). 
Table 2:

Number of Co-Authors in Leading Marketing Journals 2005-15*

\begin{tabular}{|l|c|c|}
\hline Journal Name & $\mathbf{2 0 0 5}$ & $\mathbf{2 0 1 5}$ \\
\hline Journal of Marketing Research (JMR) & 2.45 & 3.09 \\
\hline Journal of Consumer Research (JCR) & 2.31 & 2.56 \\
\hline Marketing Science (MKS) & 2.73 & 2.75 \\
\hline Journal of Marketing (JM) & 2.69 & 2.93 \\
\hline
\end{tabular}

*This includes only multi-authored papers.

Source: Authors' own calculations.

Table 3:

Changes in Editorial Board Composition over Time at JMR, JCR and MKS

\begin{tabular}{|l|c|c|}
\hline Journal Name & $\begin{array}{c}\text { \#Practitioners/Board } \\
\text { @ Founding }\end{array}$ & $\begin{array}{c}\text { \#Practitioners/Board } \\
\text { Today }\end{array}$ \\
\hline Journal of Marketing Research (JMR) & $(1964) 4 / 9$ & $0 / 140$ \\
\hline Journal of Consumer Research (JCR) & $(1974) 4 / 25$ & $0 / 150$ \\
\hline Marketing Science (MKS) & $(1984) 3 / 32$ & $0 / 100$ \\
\hline
\end{tabular}

Source: Authors' own calculations. 
Table 4:

Assessment Template for Referees

Guidelines: Please fill in - to the best of your ability - the below table, by marking where the present candidate under consideration falls in comparison to her/his cohort. Below we provide a list of 5 scholars we consider to be in the same cohort for a school we regard similar to ours in terms of standards for Promotion and Tenure, which we ask you to use to rate the candidate against.

\begin{tabular}{|c|c|c|c|c|c|c|c|c|c|c|}
\hline & \multicolumn{10}{|c|}{ Percentiles } \\
\hline & $\begin{array}{l}0 \%- \\
10 \% \\
\end{array}$ & $\begin{array}{l}10 \%- \\
20 \%\end{array}$ & $\begin{array}{l}20 \%- \\
30 \% \\
\end{array}$ & $\begin{array}{c}30 \%- \\
40 \%\end{array}$ & $\begin{array}{c}40 \%- \\
50 \% \\
\end{array}$ & $\begin{array}{l}50 \%- \\
60 \% \\
\end{array}$ & $\begin{array}{l}60 \%- \\
70 \% \\
\end{array}$ & $\begin{array}{l}70 \%- \\
80 \%\end{array}$ & $\begin{array}{l}80 \%- \\
90 \%\end{array}$ & $\begin{array}{l}90 \%- \\
100 \% \\
\end{array}$ \\
\hline \multicolumn{11}{|c|}{ Quantitative } \\
\hline \multicolumn{11}{|c|}{$\begin{array}{l}\text { Number of premier } \\
\text { journal articles }\end{array}$} \\
\hline \multicolumn{11}{|l|}{ Citations } \\
\hline \multicolumn{11}{|c|}{ Qualitative } \\
\hline \multicolumn{11}{|c|}{ Creativity } \\
\hline \multicolumn{11}{|l|}{ Novelty } \\
\hline Literacy & & & & & & & & & & \\
\hline
\end{tabular}

Cohort with which to compare the respective candidate [pre-filled by the school]:

1. Lorem Ipsum

2. Lorem Ipsum

3. Lorem Ipsum

4. Lorem Ipsum

5. Lorem Ipsum 
Figure 1:

Academic Research in Marketing and Business School Health:

Logic and Limiters

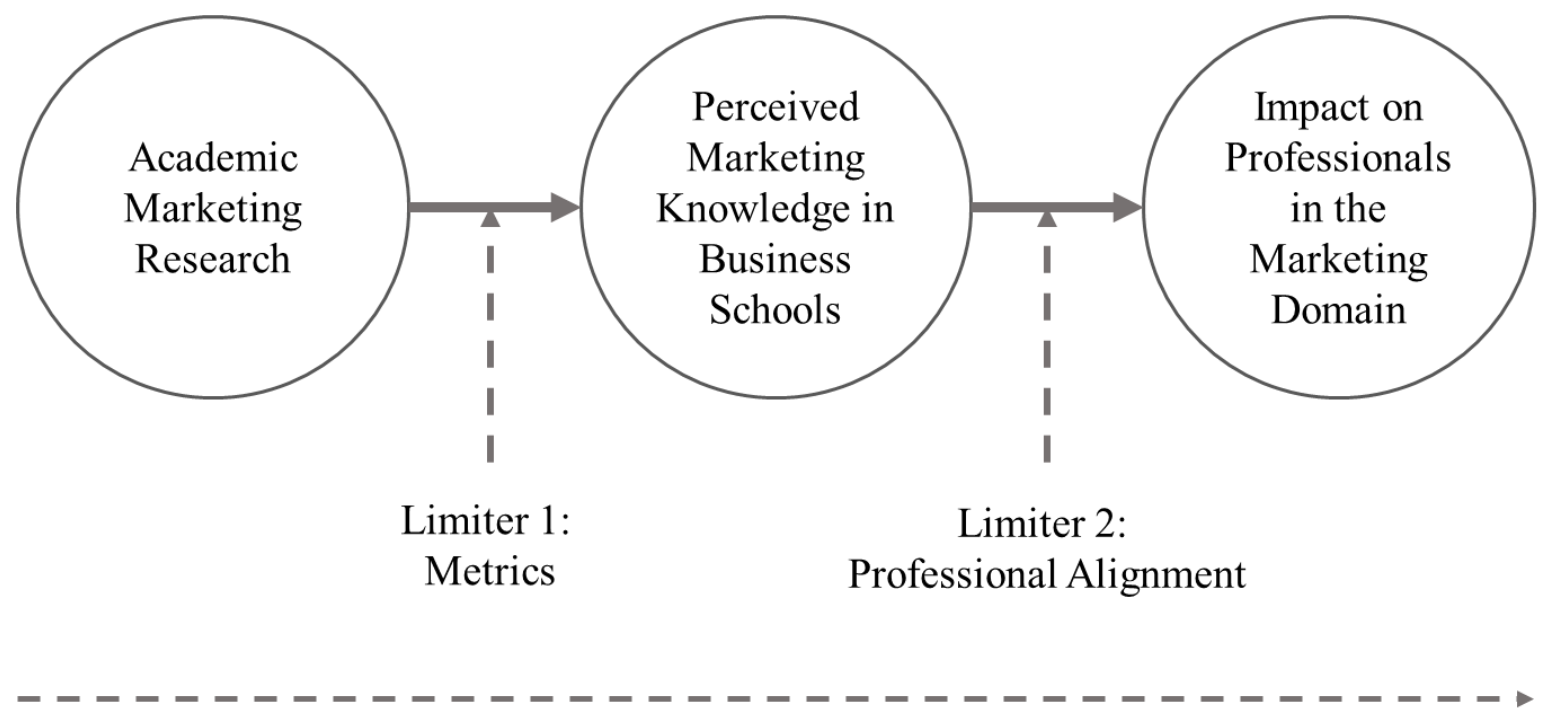

Limiter 3: Incentives 
Figure 2:

Ranking of Marketing Journals in Impact Factor Percentiles in Business Compared to Other Fields

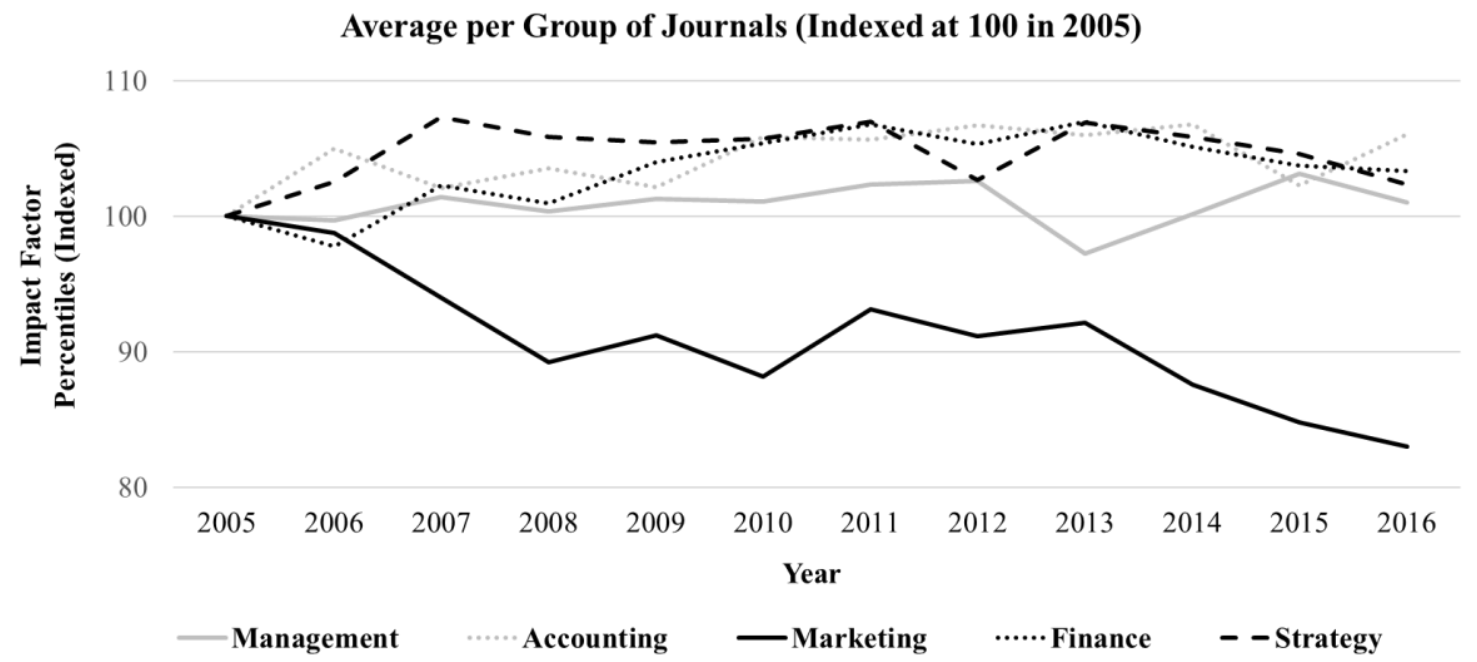

Source: Web of Science (accessed January 2018). The top journals for each field are as follows: (1) Management: Academy of Management Journal, Academy of Management Review, Administrative Science Quarterly); (2) Accounting: The Accounting Review, Journal of Accounting and Economics, Journal of Accounting Research; (3) Marketing: Journal of Consumer Research, Journal of Marketing, Journal of Marketing Research, Marketing Science; (4) Finance: Journal of Finance, Journal of Financial Economics, Journal of Financial Studies, Journal of Financial and Quantitative Analysis; (5) Strategy: Journal of International Business Studies, Organization Science, Research Policy, Strategic Management Journal. 
Figure 3:

\section{Ranking of the Individual Top Journals in Marketing in Impact Factor Percentiles in Business}

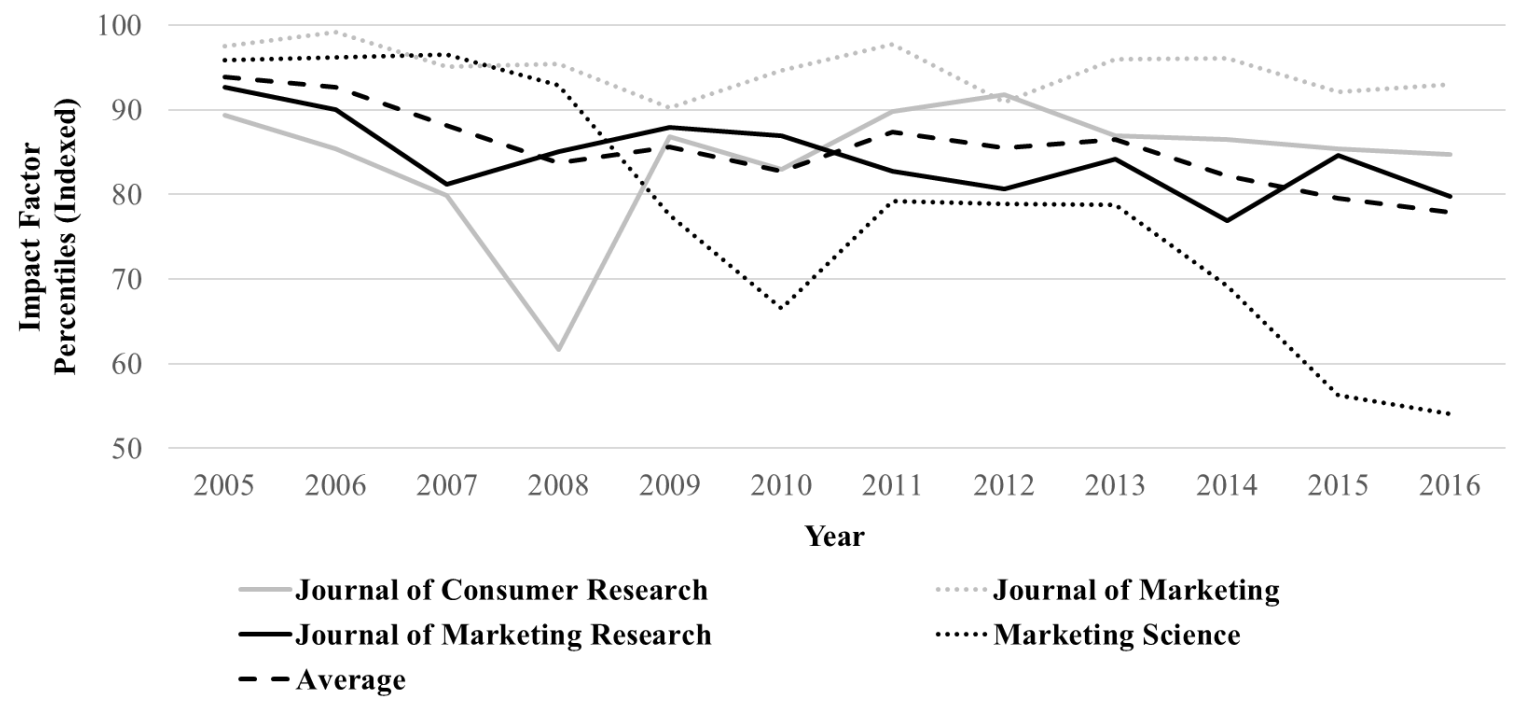

Source: Web of Science (accessed January 2018).

Figure 4:

Ranking of Top Finance Journals in Impact Factor Percentiles in Business

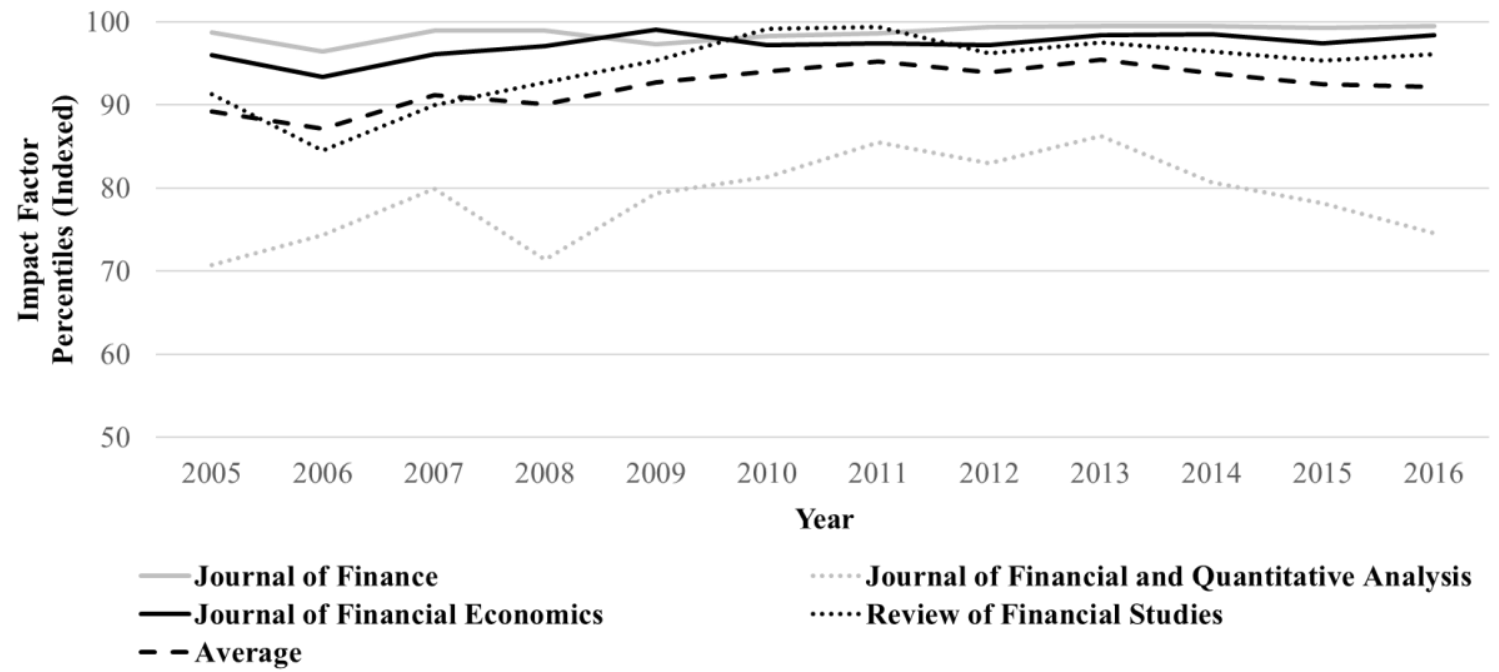

Source: Web of Science (accessed January 2018). 
Figure 5:

Percentage \% of Single Authored Papers in Four Leading Marketing Journals (1975-2015)

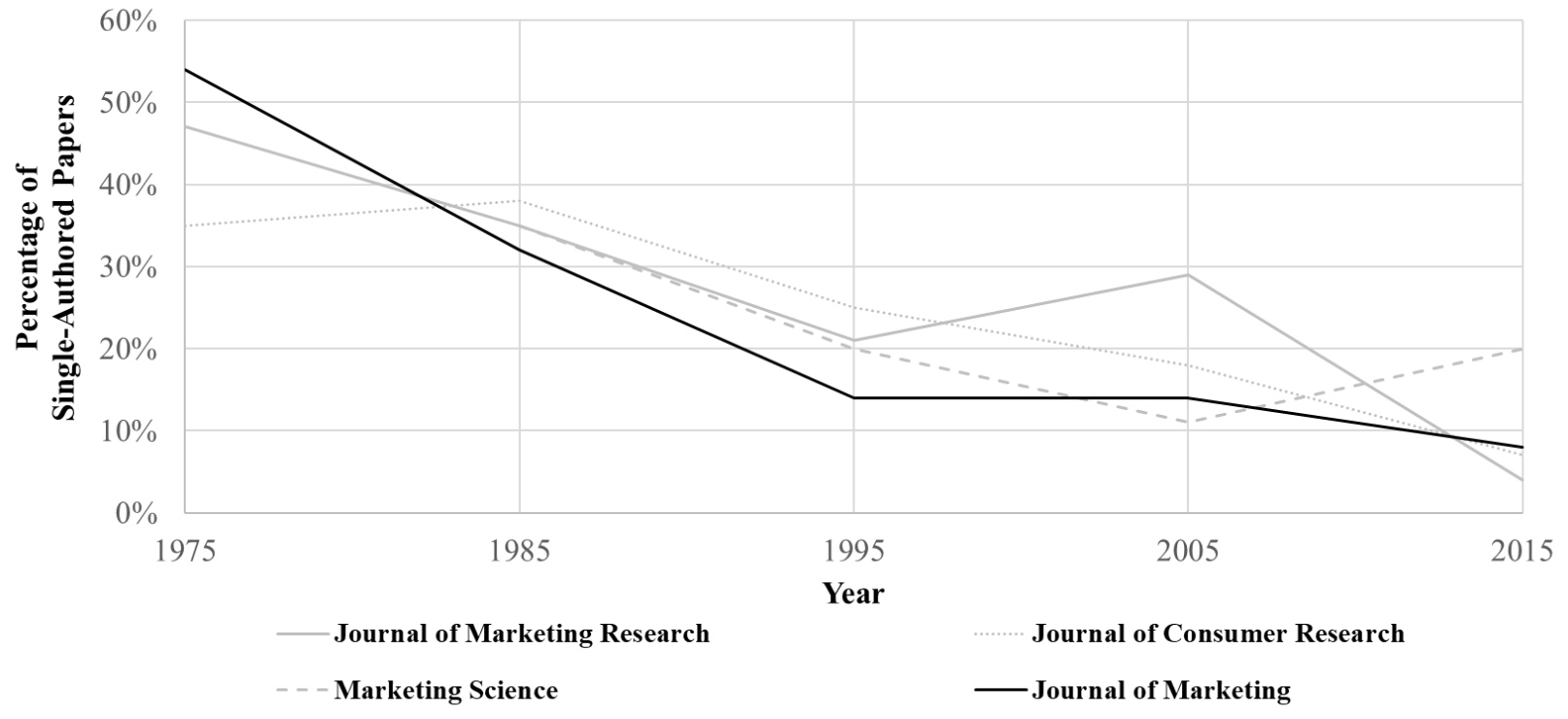

Source: Authors' own calculations. 
Figure 6:

Evolution of Attendees to the Marketing Science Conference:

Academics versus Practitioners

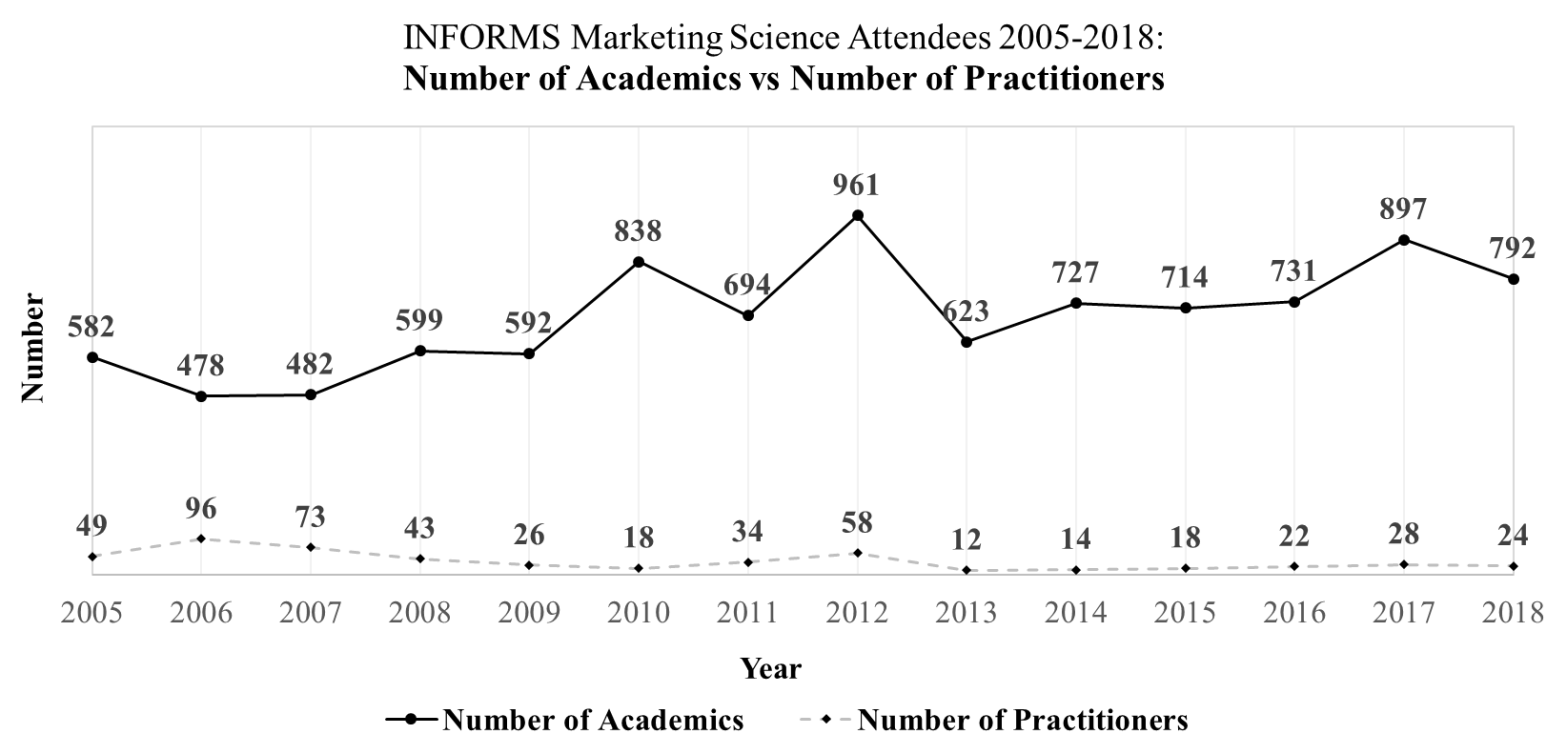

Source: Authors' own coding of academics and practitioners, based on conference attendance data of INFORMS Society for Marketing Science data, graciously provided by Doug Bowman. 
Figure 7:

Salary Evolution for Newly Appointed Assistants Professors in Marketing in USD

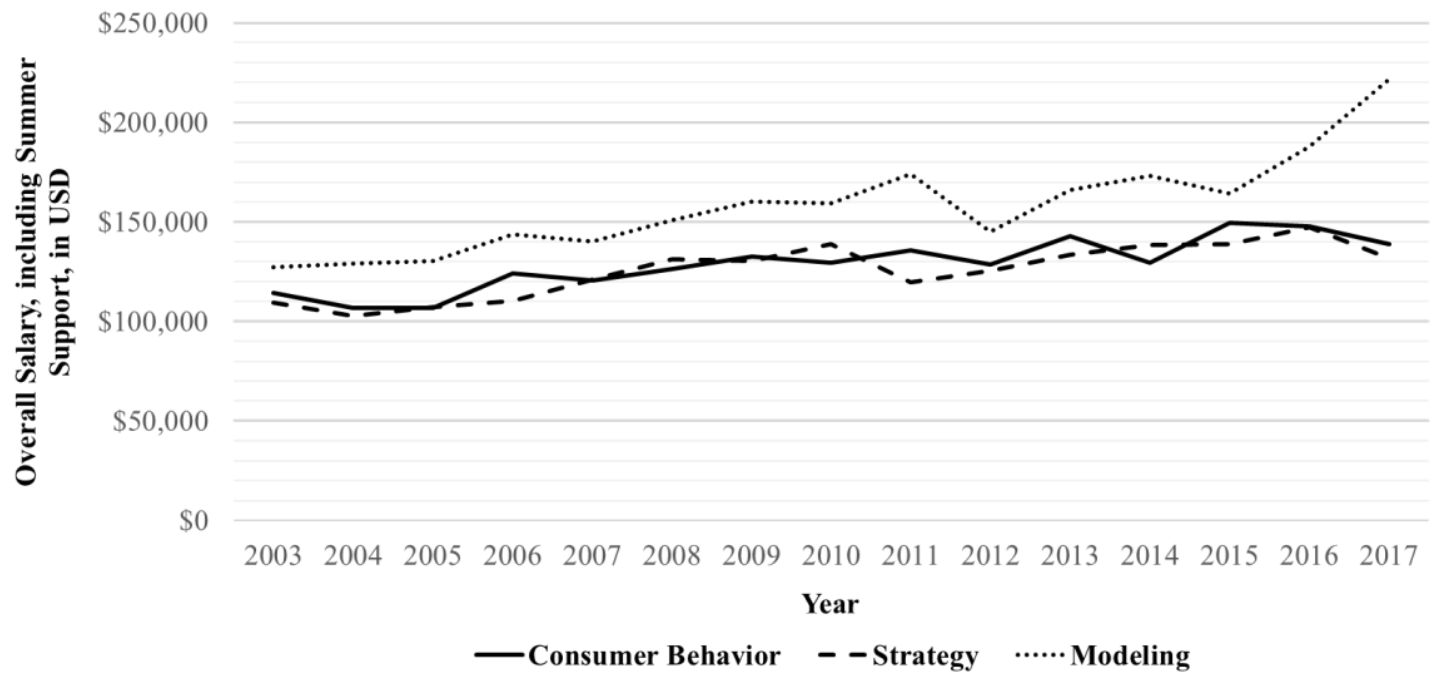

Source: Data compiled of AMA DocSig "Who Went Where? Survey Reports" (2003-2017; see http://docsig.org/who-went-where).

Figure 8:

Salary in Career Stages (2008-2016; 2- year intervals)

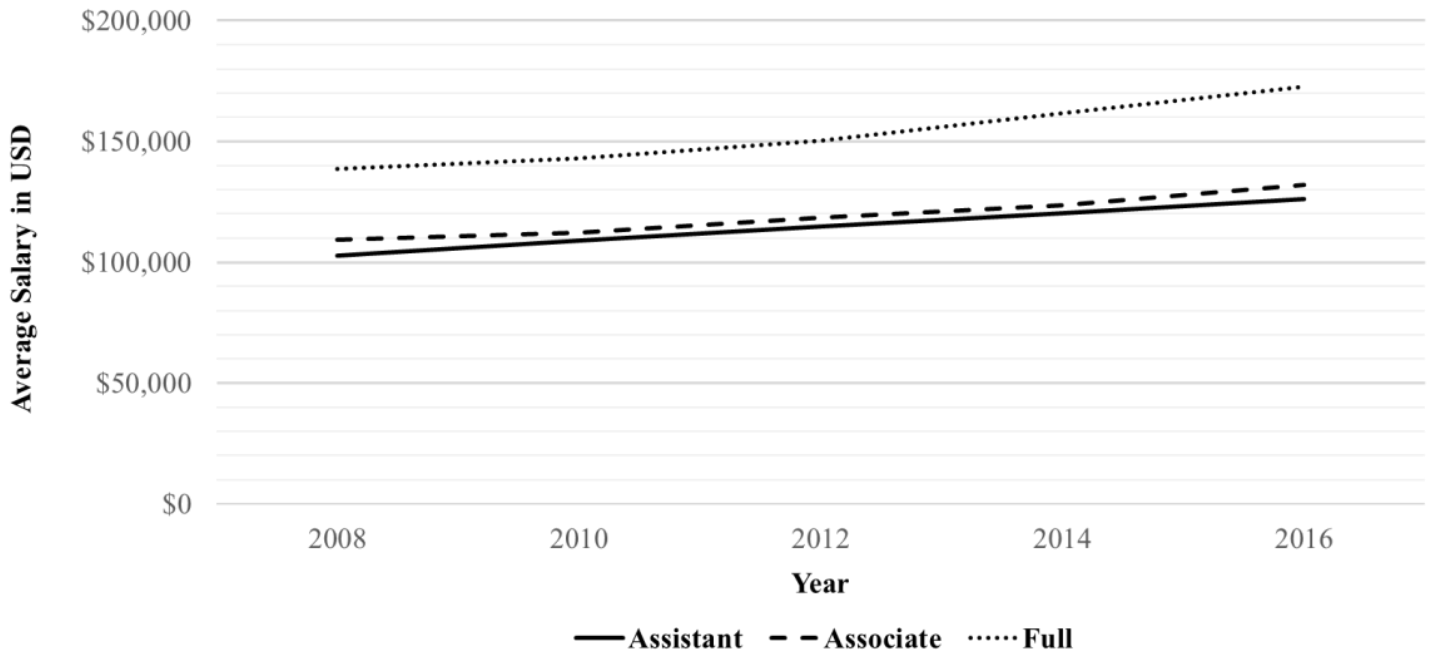

Sources: AACSB data. For example, https://www.aacsb.edu/-/media/aacsb/publications/datareports/global-salary-survey/2016-17-exec-summary.ashx?la=en. 
Figure 9:

P\&T Assessment: Input External Referees Now and Future

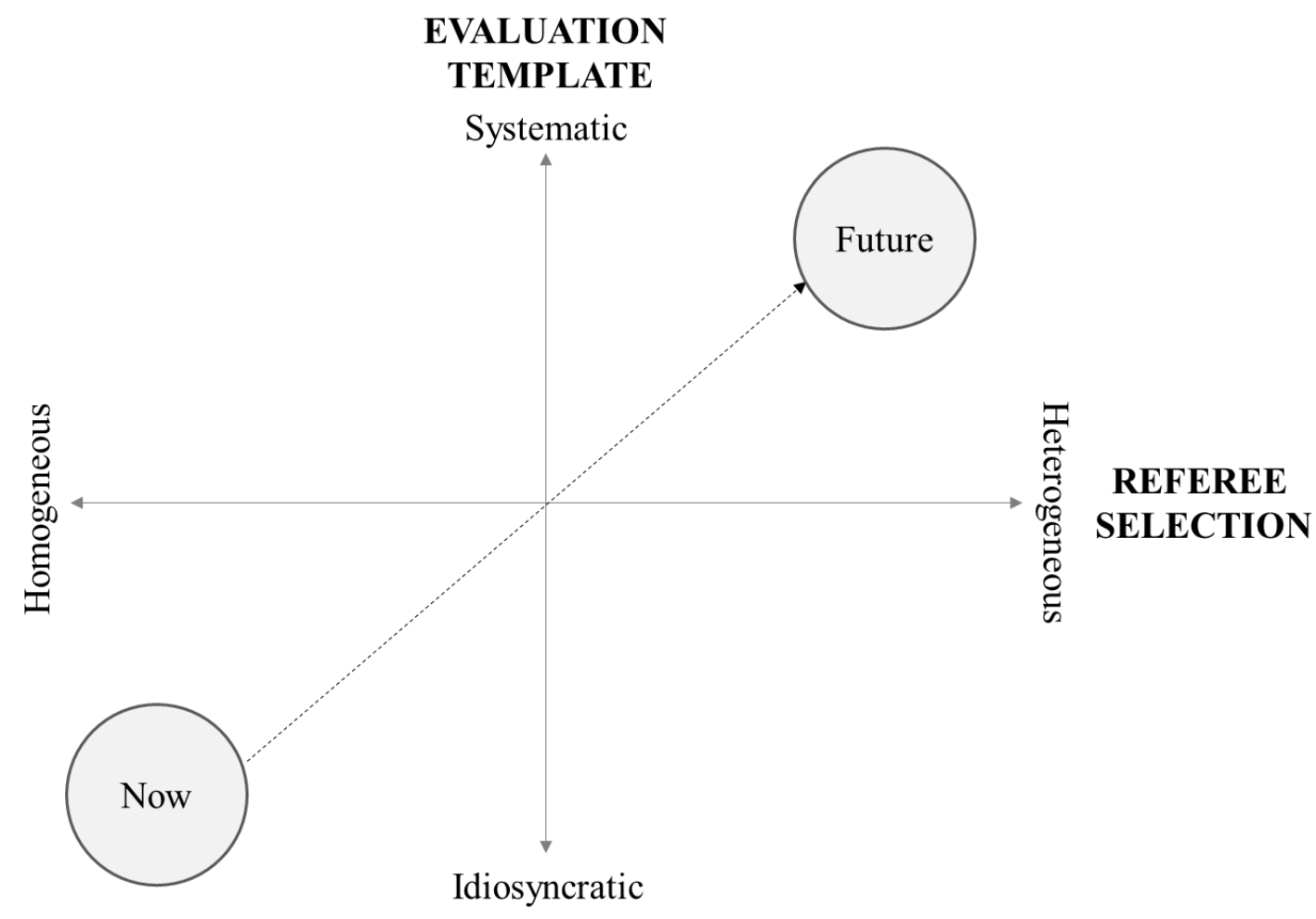




\section{REFERENCES}

Akerlof, George A. (2018), "Sins of Omission and the Practice of Economics," working paper.

Amabile, Teresa M. (1982), "Social Psychology of Creativity: A Consensual Assessment Technique," Journal of Personality and Social Psychology, 43(5), 997-1013.

Amabile, Teresa M. (1993), "Motivational Synergy: Toward New Conceptualizations of Intrinsic and Extrinsic Motivation in the Workplace," Human Resource Management Review, 3, 185-201.

Amabile, Teresa M. (1998), "How to Kill Creativity," Harvard Business Review, (September/October), 76-87.

Bénabou, Roland and Jean Tirole (2003), "Intrinsic and Extrinsic Motivation," Review of Economic Studies, 70, 489-520.

Bennis, Warren G. and James O’Toole (2005), "How Business Schools Lost Their Way,” Harvard Business Review, May, 1-9.

Bertsimas, Dimitris, Erik Brynjolfsson, Shachar Reichman, and John Silberholz (2015), "OR Forum - Tenure Analytics: Models for Predicting Research Impact," Operations Research, 63(6), 1246-1261.

Besancenot, Damien, Joao Ricardo Faria and Radu Vranceanu (2009), "Why Business Schools Do So Much Research: A Signaling Explanation," Research Policy, 1093-1101.

Besancenot, Damien, Kim Huynh, and Radu Vranceanu (2009), "The 'Read or Write' Dilemma in Academic Production: A Transatlantic Perspective," The American Economist, 53(1), 75-84.

Besemer, Susan and Karen O'Quin (1986), "Analyzing Creative Products: Refinement and Test of a Judging Instrument," Journal of Creative Behavior, 20(June), 115-126.

Bourdieu, P. (2004), Science of Science and Reflexivity, University of Chicago Press.

Bradlow, Eric T. (2008), "Editorial - Enticing and Publishing the Home Run Paper," Marketing Science, 27(1), 4-6.

Brogaard, Jonathan, Joseph Engelberg, and Edward Van Wesep (2018), "Do Economists Swing for the Fences After Tenure?" Journal of Economic Perspectives, 32(1), 179-194.

Brower, Holly Henderson and Michelle D. Steward (2015), "Business Professors Need to Spend Time in Companies," Harvard Business Review, November 27.

CMO Survey August 2018, https://cmosurvey.org/results/august-2018/.

Condry, John and James Chambers (1978), "Intrinsic Motivation and the Process of Learning," in Mark R. Lepper and David Greene (Eds.), The Hidden Cost of Reward: New Perspectives on the Psychology of Human Motivation, Chapter 4. Oxford, England: Lawrence Erlbaum. 
Deci, Edward L. (1971), "Effects of Externally Mediated Rewards on Intrinsic Motivation," Journal of Personality and Social Psychology, 18(1), 105-115.

Drucker, Peter F. (1954), The Practice of Management, New York: Harper \& Brothers.

Feng, Hui, Neil A. Morgan, and Lopo L. Rego (2015), "Marketing Department Power and Firm Performance," Journal of Marketing, 79(September), 1-20.

Frey, B. S. (1997), Not Just for the Money: An Economic Theory of Personal Motivation, Edward Elgar, Cheltenham, UK and Brookfield, USA.

Germann, Frank, Peter Ebbes, and Rajdeep Grewal (2015), “The Chief Marketing Officer Matters!" Journal of Marketing, 79(May), 1-22.

Goldenberg, Jacob, Barak Libai, Eitan Muller, and Stefan Stremersch (2010), “The Evolving Social Network of Marketing Scholars,” Marketing Science, 29(3), 561-567.

Haack, Susan (1997), "Science, Scientism, and Anti-Science in the Age of Preposterism," Skeptical Inquirer, November/December, 37-42.

Heckman, James J. and Sidharth Moktan (2018), "Publishing and Promotion in Economics: The Tyranny of the Top Five," NBER working paper number 25093, September.

Homburg, Christian, Alexander Hahn, Torsten Bornemann, and Philipp Sandner (2014), "The Role of Chief Marketing Officers for Venture Capital Funding: Endowing New Ventures with Marketing Legitimacy," Journal of Marketing Research, 51(October), 625-644.

Ioannidis, John P.A., Richard Klavans, and Kevin W. Boyack (2018), “The Scientists Who Publish a Paper Every Five Days," Nature, 561, 167-169.

Kasser, Tim and Richard M. Ryan (2001), "Be Careful What You Wish For: Optimal Functioning and the Relative Attainment of Intrinsic and Extrinsic Goals," in Life Goals and Well-Being: Towards a Positive Psychology of Human Striving, Peter Schmuck and Kennon M. Sheldon (Eds.), Chapter 8, 116-131.

Lehmann, Donald R., Leigh McAlister, and Richard Staelin (2011), "Sophisticaton in Research in Marketing,"Journal of Marketing, 75(July), 155-165.

Lilien, Gary L. (2011), "Bridging the Academic-Practitioner Divide in Marketing Decision Models," Journal of Marketing, 75(4), 196-2010.

McGraw, Kenneth O. (1978), "The Detrimental Effects of Reward on Performance: A Literature Review and a Prediction Model," in The Hidden Costs of Reward: New Perspectives on the Psychology of Human Motivation, Mark R. Lepper and David Greene (Eds.), Chapter 3. Oxford, England: Lawrence Erlbaum.

Merton, Robert K. (1968), “The Matthew Effect in Science,” Science, 159(3810), 56-63.

Mitra, Debanjan and Peter N. Golder (2008), "Does Academic Research Help or Hurt MBA Programs?" Journal of Marketing, 72(5), 31-49. 
Mittal, Vikas, Lawrence Feick, and Feishal Murshed (2008), "Publish and Prosper: The Financial Impact of Publishing by Marketing Faculty," Marketing Science, 27(3), 430-442.

Moorman, Christine, Harald van Heerde, C. Page Moreau, and Robert W. Palmatier (2018), "Why the Journal of Marketing is Important to the Marketing Discipline and a Preview of Our Editorial Philosophy," Journal of Marketing (online).

Moorman, Christine and Roland T. Rust (1999), “The Role of Marketing," Journal of Marketing, 63(Special Issue), 180-197.

Neslin, Scott A. and Russell S. Winer (2014), "The History of Marketing Science: Beginnings," in R.S. Winer and S.A. Neslin, eds. The History of Marketing Science (Singapore and Hanover, MA: World Scientific and Now publishers), Ch. 1.

Pfeffer, Jeffrey and Christina T. Fong (2002), "The End of Business Schools? Less Success Than Meets the Eye," Academy of Management Learning and Education, 1(1), 78-94.

Reibstein, David J., George Day, and Jerry Wind (2009), "Is Marketing Academia Losing Its Way?" Journal of Marketing, 73(4), 1-3.

Roberts, John H., Ujwal Kayande, and Stefan Stremersch (2014), "From Academic Research to Marketing Practice: Exploring the Marketing Science Value Chain," International Journal of Research in Marketing, 31, 127-140.

Ryan, Richard M. and Edward L. Deci (2000), "Self-Determination Theory and Facilitation of Intrinsic Motivation, Social Development, and Well-Being," American Psychologist, 55(1), 6878.

Rynes, Sara L., Jean M. Bartunek, and Richard L. Daft (2001), “Across the Great Divide: Knowledge Creation and Transfer Between Practitioners and Academics," Academy of Management Journal, 44(2), 340-355.

Schoemaker, Paul J.H. (2008), “The Future Challenges of Business: Rethinking Management Education," California Management Review, 50(3), 119-139.

Shapiro, Debra L., Bradley L. Kirkman, Hugh G. Courtney (2007), "Perceived Causes and Solutions of the Translation Problem in Management Research," Academy of Management Journal, 50(2), 249-266.

Singh, Jasjit and Lee Fleming (2010), "Lone Inventors as Sources of Breakthroughs: Myth or Reality?” Management Science, 56(1), 41-56.

Stremersch, Stefan, Nuno Camacho, Sofie Vanneste, and Isabel Verniers (2015), "Unraveling Scientific Impact: Citation Types in Marketing Journals," International Journal of Research in Marketing, 32, 64-77.

Stremersch, Stefan and Peter C. Verhoef (2005), "Globalization of Authorship in the Marketing Discipline: Does It Help or Hinder the Field?” Marketing Science, 24(4), 585-894. 
Stremersch, Stefan, Isabel Verniers, and Peter C. Verhoef (2007), “The Quest for Citations: Drivers of Article Impact," Journal of Marketing, 71(3), 171-193.

Verhoef, Peter C. and Peter S.H. Leeflang (2009), "Understanding the Marketing Department's Influence Within the Firm," Journal of Marketing, 73(March), 14-37.

Vermeulen, Freek (2005), "On Rigor and Relevance: Fostering Dialectic Progress in Management Research,” Academy of Management Journal, 48(6), 978-982.

Wang, Jian, Reinhilde Veugelers, and Paula Stephan (2017), "Bias Against Novelty in Science: A Cautionary Tale for Users of Bibliometric Indicators," Research Policy, 46, 1416-1436.

Webster, Frederick E. Jr and Robert Lusch (2013), "Elevating Marketing: Marketing Is Dead! Long Live Marketing!” Journal of the Academy of Marketing Science, 41, 389-399.

Wittink, Dick R. (2001), 'Market Measurement and Analysis: The First 'Marketing Science' Conference," Marketing Science, 20(Fall), 349-356.

Yadav, Manjit S. (2010), "The Decline of Conceptual Articles and Implications for Knowledge Development," Journal of Marketing, 74(1), 1-19. 